
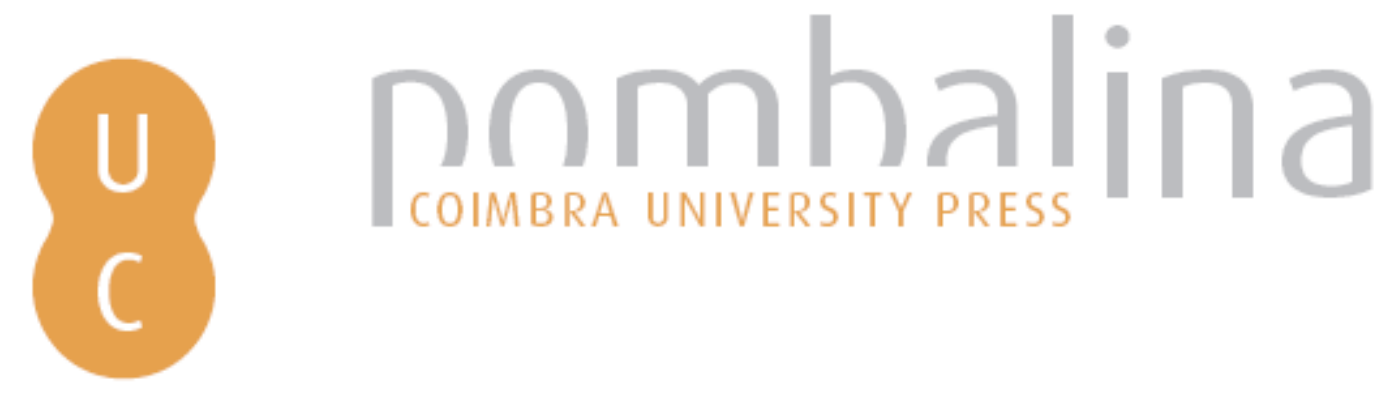

\title{
Las redes sociales en la organización de movimientos ciudadanos en regímenes totalitarios: el caso de la "Primavera árabe"
}
Autor(es):
Silva, Xosé Baamonde
Publicado por: Imprensa da Universidade de Coimbra
URL
persistente:
URI:http://hdl.handle.net/10316.2/39014
DOI:
DOI:http://dx.doi.org/10.14195/978-989-26-1064-1_20
Accessed : $\quad$ 26-Apr-2023 02:40:20

A navegação consulta e descarregamento dos títulos inseridos nas Bibliotecas Digitais UC Digitalis, UC Pombalina e UC Impactum, pressupõem a aceitação plena e sem reservas dos Termos e Condições de Uso destas Bibliotecas Digitais, disponíveis em https://digitalis.uc.pt/pt-pt/termos.

Conforme exposto nos referidos Termos e Condições de Uso, o descarregamento de títulos de acesso restrito requer uma licença válida de autorização devendo o utilizador aceder ao(s) documento(s) a partir de um endereço de IP da instituição detentora da supramencionada licença.

Ao utilizador é apenas permitido o descarregamento para uso pessoal, pelo que o emprego do(s) título(s) descarregado(s) para outro fim, designadamente comercial, carece de autorização do respetivo autor ou editor da obra.

Na medida em que todas as obras da UC Digitalis se encontram protegidas pelo Código do Direito de Autor e Direitos Conexos e demais legislação aplicável, toda a cópia, parcial ou total, deste documento, nos casos em que é legalmente admitida, deverá conter ou fazer-se acompanhar por este aviso.

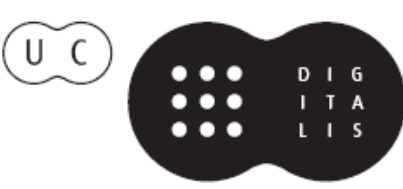


A L B ERTO PENA-RODR ÍGUEZ HELOISA PAULO

COOR D.

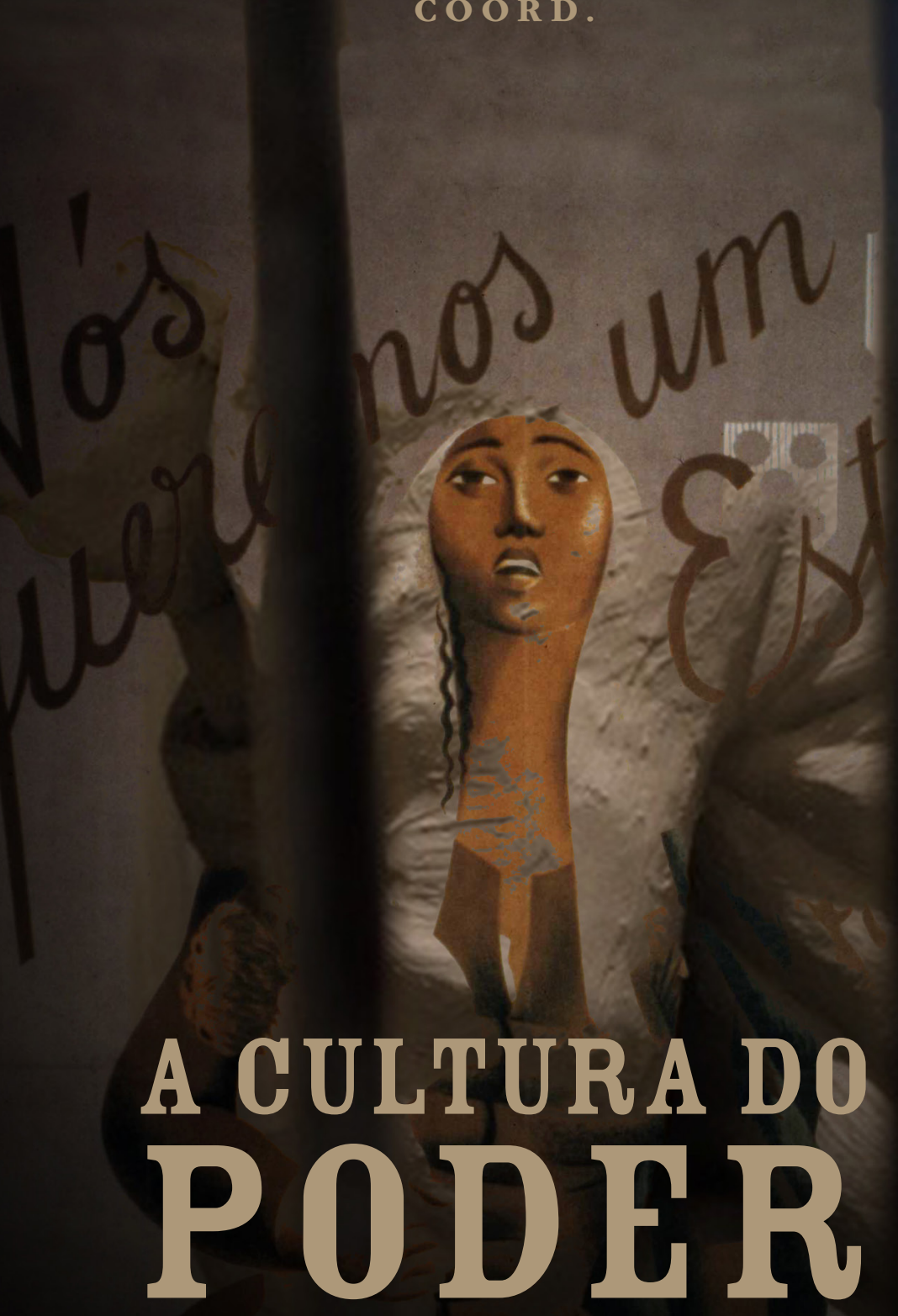

A PROPAGANDA INOS ESTADOS AUTORITÁRIOS 


\section{LAS REDES SOCIALES EN LA ORGANIZACIÓN DE MOVIMIENTOS CIUDADANOS \\ EN RE GíM ENES TOTALITARIOS. \\ ELCASO DE LA “PRIMAVERA ÁRABE"}

Xosé Baamonde Silva

\section{Introducción}

La aparición de Internet ha provocado cambios sustanciales en la forma en la que los ciudadanos canalizan su descontento frente a las decisiones de los gobernantes. Incluso en los regímenes totalitarios, los gobiernos, cada vez más, se ven en la obligación de explicar las decisiones que toman ante sus súbditos.

La participación ciudadana en los asuntos públicos ha ido creciendo hasta el punto de que los poderes tradicionales se han visto forzados a compartir, o por lo menos justificar, las medidas adoptadas que afecten al futuro de la sociedad. Para ello, tradicionalmente, recurrían a los medios de comunicación como catalizadores de sus mensajes, fundamentalmente propagandísticos, hacia la opinión pública. Con la irrupción de las nuevas posibilidades y servicios que ofrecen Internet, la Web $2.0 \mathrm{y}$, especialmente, las redes sociales, se produce un nuevo escenario.

El futuro de Internet trae consigo un nuevo ciudadano digital, más crítico y con mayores posibilidades de implicarse y comprometerse 
con la gestión del bien común. Este trabajo analiza los movimientos ciudadanos espontáneos que tienen en la utilización de Internet y las redes sociales una de sus señas de identidad y que jugaron un papel esencial en la denominada "Primavera árabe".

Los acontecimientos vividos en los países árabes demuestran que las reglas del juego de la comunicación política están cambiando radicalmente y que estos cambios afectan a la naturaleza de las relaciones entre gobernantes y gobernados. Además, la proyección y consecuencias de estas transformaciones tienen un impacto global e inmediato.

Las redes sociales han sido determinantes para el triunfo de unos movimientos políticos ciudadanos sin líderes y sin estructura ni organización aparentes y, también, el ejemplo más claro de que la comunicación política -en todas sus vertientes- no será como la hemos conocido hasta ahora.

\section{El detonante de la "Primavera árabe"}

La denominada "Primavera árabe" agrupa los movimientos populares de protesta realizados en diversos países, iniciados a finales del año 2010. Un joven tunecino, Mohammad Bouazizi, vendedor ambulante, intimidado por la policía, se inmola el 17 de diciembre de 2010 y desencadena una corriente de revuelta que se extiende por todo el país. Aunque que el régimen dirigido por Ben Alí había logrado cierto grado de desarrollo económico, estaba concentrado en pocas manos y la mayoría de la sociedad vivía en la pobreza. Mohammad Bouazizi muere el 4 de enero de 2011. Las manifestaciones se extienden desde las periferias de Túnez hasta su misma capital. Ben Ali recurre al ejército, pero este se rebela y por boca de su jefe se niega a disparar contra la multitud. El régimen se derrumba y el dictador, acosado, huye el 14 de enero de 2011. 
La inmolación de los jóvenes se convirtió en un acto de propaganda, de protesta y de comunicación política ante unas condiciones indignas de vida y la saturación de una situación basada en las desigualdades económicas y en la ausencia de libertades. Siguiendo lo acontecido en Túnez, una explosión política similar tuvo lugar en Egipto.

Las protestas en Egipto comenzaron el 25 de enero de 2011 y se prolongaron durante 18 días hasta el derrocamiento del gobierno de Hosni Mubarak, después de casi 30 años al frente del país. La importancia que el régimen otorgó a las redes sociales queda demostrada en el hecho de que, el 27 de enero, cortó las líneas de telefonía móvil e internet para impedir la coordinación de los activistas. La solución del movimiento social fue recurrir a los métodos tradicionales. La oposición en la calle estuvo constituida por una minoría, pero una minoría activa y decisiva, frente a una mayoría bautizada en Egipto como "la mayoría del sofá". Al igual que en Túnez, el papel del ejército fue fundamental. Una vez que el Consejo Supremo de las Fuerzas Armadas accedió al poder decidió la disolución del Parlamento, la suspensión de la Constitución y prometió levantar el estado de emergencia y la convocatoria de elecciones libres.

La evolución de las protestas populares fue vertiginosa, pues lograron derrocar regímenes consolidados en menos de un mes. Sin creer en el milagro de lo imprevisible, esta claro que la situación ya estaba madura para una conflagración generalizada: bastaba con un hecho que sirviera de detonante. La sociedad estaba preparada pues, como indica la periodista especializada en Oriente Medio, Olga Rodríguez, sólo desde la certeza de que el cambio es factible se puede protestar y luchar, arriesgando incluso la propia vida.

${ }^{1}$ RODRÍGUEZ, Olga. Yo muero hoy. Las revultas en el mundo árabe, Barcelona: Editorial Debate, 2012 
El éxito de los movimientos sociales se basa en la toma de conciencia de uno mismo como ciudadano y no como súbdito. Uno de los aspectos que más destacaron quienes participaron en las revueltas es su orgullo por poder formar parte de un proyecto colectivo en el que había cabida para todos. Las revueltas no tienen dueños ni protagonistas, fueron fruto de un trabajo colectivo y anónimo que, en cierto modo, no podría haber avanzado sin la aportación de cada uno de sus participantes.

Antes de avanzar en el análisis de la evolución de la "Primavera árabe" en los dos países más representativos de este momento histórico, consideramos procedente revisar los motivos de la longevidad de los sistemas autoritarios en esa zona ${ }^{2}$. Se trata de explicar por qué han esperado tanto, mientras que en España y Portugal, la ola de democratización había acabado con los regímenes de Franco y de Salazar en los años setenta, con las dictaduras de América Latina en los ochenta, y con los países de Europa Central y Oriental en los noventa. Hay factores internos y factores externos.

En primer lugar, los factores internos reflejan la naturaleza del Estado árabe poscolonial. Una vez atravesado el umbral de la independencia, el problema de la afirmación nacional prevalece sobre todo el resto. Estos equipos militares se presentan como los "salvadores de la nación árabe de las garras del colonialismo» y como los "artífices del desarrollo de las sociedades», pero rápidamente caen en un populismo primario, amordazando cualquier intento de disidencia y acusando de "agentes del imperialismo" a todos aquellos que se les oponen. Otro elemento que contribuye a la perduración de estos gobiernos totalitarios, en los países productores de petróleo, es la renta petrolífera, que actúa como un amortiguador de las protestas. También la cuestión palestina ha ido en contra de

\footnotetext{
2 KHADER, Bichara. "Túnez y el despertar democrático árabe", en el Anuario del Instituto Europeo del Mediterráneo, Barcelona, IEMed, 2011
} 
la democracia, pues el mensaje emanado desde el poder llamaba a cerrar filas contra el enemigo sionista.

En cuanto a los factores externos, hay que referirse a la alianza de estos regímenes con las grandes potencias durante la guerra fría como un elemento determinante para su longevidad. Ello se debe a su riqueza geológica (gas y petróleo), a su localización geográfica (región clave - corredor - encrucijada), a su importancia geopolítica y geoestratégica (conecta el Mediterráneo con los océanos, y bordea África, Europa y Asia), a su interés económico (se trata de uno amplio mercado), e incluso a su dimensión geoteológica (la zona está dotada de una especie de "geografía sagrada" para las tres religiones monoteístas). Por tanto, la guerra fría contribuyó a congelar las reivindicaciones democráticas y a la fosilización de los regímenes.

Además, estos gobiernos totalitarios se han presentado como los garantes de la estabilidad, tan necesaria para los flujos regulares de petróleo y el gas. Asimismo, se han presentado cómo las murallas contra él islamismo, contra los yihadistas y como los centinelas contra la inmigración.

\section{Causas de las revueltas árabes}

La "Primavera árabe", protagonizada por amplios y diferentes sectores de la sociedad, ha tenido importantes consecuencias sobre los regímenes y sistemas políticos árabes 3 . Ocasionó la apertura de procesos de cambio político en el norte de África y Oriente Próximo, que continúan abiertos y que siguen ritmos desiguales. Sin embargo, no se puede afirmar que se haya producido un tsunami democrático en la región.

3 SZMOLKA, Inmaculada. Factores desencadenantes y procesos de cambio político en el Mundo Árabe, Barcelona: CIDOB, 2012 
El malestar árabe nace de situaciones similares aunque no idénticas. Cada país tiene sus peculiaridades y, por lo tanto, no sería correcto atribuir a todos los levantamientos populares las mismas causas. No obstante, es posible señalar algunos factores comunes: todos ellos estuvieron marcados por la corrupción, la falta de libertad, la represión contra todo tipo de disidencia y las grandes desigualdades sociales y económicas.

Las revueltas son el resultado de una acumulación de frustraciones sin resolver debido a unos regímenes autocráticos que se perpetúan desde la noche de los tiempos (el autoritarismo fue la norma y no la excepción), una democracia de fachada que ha devenido en un sistema pluralista autoritario, una gerontocracia desconectada de la realidad que se aferra al poder, una corrupción endémica que ha consumido las estructuras de gobierno, una asfixiante persecución de toda discrepancia política y una sistemática vulneración de la libertades fundamentales. Este déficit de legitimidad popular de los gobernantes ha sido contrarrestado a menudo con una sobreactuación del aparato coercitivo cuando las demandas de la población se elevaban demasiado.

Esta radiografía quedaría incompleta sin aludir al agudo deterioro económico. En primer lugar, un Estado benefactor incapaz de hacer frente por más tiempo a las crecientes necesidades de la población (vivienda, educación y sanidad) y a la incorporación al mercado laboral de los hijos del 'baby boom' árabe. En segundo lugar, existe una desigual repartición de la riqueza, ya que el fuerte crecimiento registrado en los últimos años tan sólo ha favorecido a un reducido grupo asociado con el poder, principal beneficiario de los procesos de privatización de las empresas públicas. Mientras tanto, las condiciones de vida del grueso de la población experimentaron un agudo retroceso. Un $45 \%$ de los ochenta millones de egipcios vivía bajo el umbral de la pobreza, al igual que un $30 \%$ de los sirios. Debe tenerse en cuenta que un $65 \%$ de la población árabe tiene 
menos de 35 años y que la mitad de ellos (cerca de 100 millones de personas) tiene entre 15 y 29 años. Los índices de desempleo entre los jóvenes son excepcionalmente elevados, hecho que impide que puedan formar una familia o acceder a una vivienda y, a la vez, genera una elevada frustración.

Según Álvarez-Osorio ${ }^{4}$, la población perdió el miedo a sus gobernantes y a sus aparatos represivos y tomó las calles demandando mayores libertades y el fin de las autocracias. Las protestas fueron, ante todo, una muestra de descontento hacia unos gobernantes que se perpetúan en el tiempo y que gestionaron los recursos estatales como si fueran de su propiedad. En definitiva, los manifestantes salieron a la calle para decir "basta ya" de tanta frustración y en demanda de mayores cuotas de libertad y de democracia.

\section{El activismo en los países árabes y el papel de las redes sociales}

Las revueltas árabes de 2011 no surgieron por generación espontánea. Detrás de ellas hay una historia de lucha por un cambio real a través del activismo clandestino, de la defensa de los derechos humanos, de los movimientos obreros, de las agrupaciones que llevaban años trabajando por la justicia social. Hoy en día, existen cerca de 125.000 asociaciones vinculadas a la sociedad civil en los veintiún países árabes.

La constancia de la militancia de unos pocos sentó las bases y creó los cauces para canalizar el hartazgo de muchos. Sin unos y

4 ÁLVAREZ-OSORIO, Ignacio. "Las revoluciones árabes: hacia un cambio de paradigma”, en MESA, Manuel (coord.), El mundo a la deriva: crisis y pugnas de poder, Madrid: CEIPAZ-Fundación Cultura de Paz, 2011. 
otros las revueltas no habrían tenido lugar. Podemos considerarlas como un nuevo ejemplo de una estrategia basada en la resistencia pacífica: "grupos en todo el mundo han adoptado la resistencia civil con una multitud de propósitos: resistir al colonialismo; enfrentarse a una invasión u ocupación extranjeras; contestar elecciones arregladas, dictaduras de gobiernos militares; lograr derechos para las minorías o erradicar la discriminación institucional"5.

Estos movimientos de protesta en el mundo árabe tienen algunos rasgos característicos: el ser un fenómeno nuevo, su espontaneidad, su desideologización y su heterogeneidad. La socióloga y politóloga Theda Skocpol demostró hace tiempo que no sólo era necesaria la desafección de la ciudadanía del poder para la caída de los regímenes autoritarios, sino que lo verdaderamente relevante era que este pueda mantener los medios de coerción para evitar una revolución ${ }^{6}$.

En el caso de Túnez y Egipto, lo que marcó él éxito de las revoluciones populares fue la decisión del ejército, pilar fundamental en ambos regímenes, de no intervenir contra los manifestantes. Por tanto, lo que ha definido el éxito de las revoluciones populares es sí se ha producido una fractura entre la élites dirigentes y las élites sustentadoras del régimen. Así, los países árabes no se diferencian de anteriores experiencias en las que el principal detonante de los procesos de cambio político fue la división de las élites dentro del sistema político ${ }^{7}$.

También es necesario señalar que la comunidad internacional no ha estado a la altura de las circunstancias. El silencio de la mayoría

5 STEPHAN, Maria. Civilian Jihad. Nonviolent Struggle, Democratization and Governance in the Middle East, Nueva York: Palgrave MacMillan, 2009.

6 SKOCPOL, Theda,. States and Social Revolutions. Nueva York: Cambridge University Press, 1979.

7 O'DONNELL, Guillermo; SCHMITTER, Philippe y WHITEHEAD, Laurence, Transitions from Authoritarian Rule: Tentative Conclusions about Uncertain Democracies. Baltimore: Johns Hopkins University Press, 1986. 
de los países occidentales ante la represión de las manifestaciones pacíficas ha sido esclarecedor y ha reforzado la imagen de un Occidente con un doble discurso que, por una parte, echa mano a la retórica de la democracia y los derechos humanos cuando le conviene y, por la otra, se alinea con las dictaduras que oprimen a sus pueblos con el pretexto de que sirven de muro de contención al radicalismo islámico. La sociedad civil árabe ha sido protagonista y artífice de esta primavera democrática.

En este contexto, las redes sociales han tenido un trascendental y novedoso papel en la organización de las concentraciones reivindicativas. La gran diferencia entre estos movimientos y anteriores protestas es la definitiva consolidación de Internet como una herramienta para convocar manifestaciones y para difundir información. Como señala el profesor Manuel Castells, la principal característica de la comunicación inalámbrica no es la movilidad sino la conectividad perpetua ${ }^{8}$. La Red actuó como un lugar de encuentro para los activistas, que no precisaban de estar en el mismo lugar para comunicarse y podían relacionarse permanentemente con gente similar tras pagar un ordenador y una conexión a Internet. Aunque, es preciso reconocer que su eficacia habría sido menor si la cadena Al Jazeera (cadena preferida por los árabes para estar informados), con millones de espectadores, no se hiciera eco de las convocatorias. El trabajo conjunto de las redes sociales y las cadenas por satélite fue capaz de romper el monopolio estatal sobre la información.

Es pertinente citar como precedente el papel jugado por los blogs en las protestas del año 2005, a partir del cual estas bitácoras personales se convirtieron en los sustitutos de los medios de comunicación tradicionales. Así lo explica la destacada ciberactivista

8 CASTELlS, Manuel. Comunicación y Poder, Madrid: Alianza Editorial, 2010 
egipcia, Manal Hassan': los bloggers que ya habían recibido algo de atención, que habían crecido y tenían un nombre en la red, estaban participando en la protesta y la estaban cubriendo y contando lo que sucedía. Con cámaras o teléfonos móviles, ellos ponían en la red todo el material. Además se encargaron de recopilar todas las fotos, vídeos y testimonios, incluso SMS que se habían enviado entre los manifestantes y sus amigos cuando pedían ayuda, cuando contaban qué es lo que sucedía. Es muy importante tener este tipo de medios ciudadanos porque los periódicos no cubren todas las ciudades, todos los lugares en Egipto. Sólo recogen algunas noticias sobre El Cairo, probablemente algunas sobre Alejandría, por lo que es muy importante tener bloggers locales para saber qué es lo que sucede en sus ciudades, qué eventos son importantes o qué problemas hay. Se necesitan bloggers locales para que den su propia perspectiva, lo que sienten y lo que pasa.

La tecnología jugó un papel vital a la hora de comunicar el mensaje de los activistas y fue un elemento fundamental para organizar la estructura interna, pues gracias a ella pudieron contactar con gente que vivía a mucho kilómetros de distancia, mantener reuniones a través de un grupo secreto en una página de Facebook o de Skype para estar en contacto continuo y planear la estrategia. Todos estos avances tecnológicos ayudaron a la consolidación de la Red como herramienta de información, de difusión de ideas y de agitación. Las redes sociales, como Facebook y Twitter, tuvieron un peso esencial al convocar las manifestaciones y reclutar a nuevos activistas.

Tanto o más importante fue el valor de la Red como enlace entre los jóvenes que apoyaban los cambios desde el exterior y los que participaban directamente en las manifestaciones. Internet y las redes

\footnotetext{
9 Entrevista a Manal Hassan en http://www.periodismociudadano.com/2013/03/06/ manal-hassan-y-la-importancia-de-los-blogueros-en-egipto/, consultada el 26 de agosto de 2013
} 
sociales funcionaron como elementos de apoyo al proceso y como contrapeso a la censura oficial y a los medios afines al régimen, y fueron útiles para superar el aislamiento de la sociedad árabe, para hacer visibles los conflictos y para conseguir apoyos relevantes en el exterior ${ }^{10}$.

Los intentos de los gobiernos para lograr un "apagón" en las comunicaciones fueron vanos. Twitter fue uno de los primeros servicios en ser bloqueados en Egipto, situación que provocó la migración de los usuarios a otras redes sociales como Facebook y Tumblr. Facebook fue la siguiente en ser cercada. Con cada red bloqueada aumentaba la indignación entre los usuarios de esas mismas redes en el extranjero que veían desaparecer mensajes y amigos de su pantalla. Tras el aislamiento de las redes sociales cayeron las redes de datos móviles: el servicio de BlackBerry fue el primero en ser eliminado; luego los mensajes de texto (SMS) y correos electrónicos (MMS). La gente recurrió a las líneas telefónicas convencionales como el fax que funcionaba normalmente y que fue utilizado como línea de noticias, hasta que la noche del 27 al 28 de enero de 2011, los cuatro proveedores principales de Egipto acataron las directrices del gobierno y dejaron aislados a sus usuarios cortando completamente las comunicaciones ${ }^{11}$.

Pese a reconocer la contribución de las redes sociales para permitir a los ciudadanos derrocar regímenes dictatoriales (que ha llevado a algunos a denominar las revueltas en los países árabes como "Twitter Revolution"), hay que indicar que las fórmulas tradicionales de comunicación, desde el fax hasta los grupos de seguidores de

10 SOENGAS, Xosé, "El Papel de Internet y de las redes sociales en las revueltas árabes: una alternativa a la censura de la prensa oficial", revista Comunicar, n. ${ }^{\circ} 41$, pp. $147-155,2013$

11 DURANTE, Esther, "Trascendencia del uso de las redes sociales y el BlackBerry Messenger en la mundialización de disturbios civiles en Oriente Medio, Europa y Norteamérica”, Quórum Académico, vol. 9, n. ${ }^{\circ}$ 1, enero-junio 2012, pp. 86-104. 
futbol, pasando por las grandes concentraciones de protesta se realizaran en las plazas, tuvieron una función decisiva en el triunfo de la revolución. En los movimientos revolucionarios también es necesario tomar las calles, construir barricadas (que tienen poca eficacia defensiva pero distinguen a los que están de uno y otro lado) y, sobre todo, unirse para superar el miedo ${ }^{12}$.

En todo caso, sí es posible hablar de las redes sociales como un nuevo campo de batalla propagandístico, como lo demuestra el hecho de que el propio ejército egipcio abriera un perfil en Facebook para transmitir sus puntos de vista y, ya en el año 2013, el presidente egipcio, Mohamed Morsi, rechazara el ultimátum militar a través de su cuenta de Twitter ${ }^{13}$.

El profesor Manuel Castells explica que a lo largo de la historia, la comunicación y la información han sido las fuentes fundamentales del poder y del contrapoder, de la dominación y del cambio social. Y ello es debido a que la batalla fundamental se da en las mentes de las personas. Cierto es que el poder también se basa, de acuerdo a la vieja tradición de Maquiavelo y Max Weber, en el monopolio legítimo o ilegítimo de la violencia. Quienes controlan los medios de la violencia tienen una capacidad de imponer sus intereses. De hecho, un sistema de poder que se basa sólo en la coacción es un poder débil, porque si una gran parte de las personas son capaces de pensar diferente y de atreverse a traducir en la práctica ese pensar diferente, ese poder coactivo acaba disolviéndose. Torturar los cuerpos es menos efectivo que modelar las mentes ${ }^{14}$.

12 CASTELLS, Manuel. Redes de Indignación y Esperanza. Los movimientos sociales en la era de Internet, Madrid: Alianza Editorial, 2012

13 REYES, ALVARO, Presidente egipcio rechazó ultimátum militar desde twitter, en http://www.clasesdeperiodismo.com/2013/07/03/presidente-egipcio-rechazo-ultimatum-militar-desde-twitter/, consultada el 26 de agosto de 2013

14 CASTELLS, Manuel. "El poder en la era de las redes sociales", Nexos en línea, 1 septiembre de 2012 


\section{Evolución de la "Primavera árabe"}

La evolución de la denominada "Primavera árabe" ha causado cierto pesimismo por la vitoria de los partidos islamistas en las elecciones celebradas tanto en Túnez como en Egipto. El hecho de que las revueltas no hayan abierto un proceso de secularización como muchos esperaban ${ }^{15}$, sino que hayan allanado el camino para la conquista del poder por parte de los islamistas ha llevado a algunos a lanzar la voz de alarma por la supuesta existencia de una agenda oculta por parte de los movimientos islamistas. Este temor es compartido tanto por los países occidentales como por los activistas y defensores de los derechos humanos en el mundo árabe, que sospechan de las verdaderas intenciones de estos partidos una vez en el gobierno.

El amplio respaldo popular que cosecharon en las urnas vino a premiar tanto la labor social desarrollada en las últimas cuatro décadas como el pragmatismo del que habían hecho gala en los últimos años. Los movimientos islamistas han reconocido la pluralidad de las sociedades árabes (en lo ideológico y confesional) $\mathrm{y}$, en consecuencia, parecían dispuestos a renunciar a imponer por la fuerza sus concepciones aceptando, con ello, los principios democráticos (incluida la alternancia en el poder).

En opinión de Ignacio Álvarez-Osorio, los perdedores de los procesos electorales fueron los jóvenes que desencadenaron la revolución y que fueron incapaces de traducir su capacidad de movilización en peso político en el nuevo escenario post-Primavera Árabe. Junto a ellos, las grandes derrotadas en este nuevo escenario pueden ser las mujeres, que han visto reducida su presencia en la

15 ÁLVAREZ-OSORIO, Ignacio. "Primavera democrática árabe: ¿otoño islamista?”, en MESA, Manuela, Cambio de ciclo: crisis, resistencias y respuestas globales, Madrid, CEIPAZ-Fundación Cultura de Paz, 2012. 
vida política y que podrían ser las principales afectadas en el caso de que se reformen los códigos de familia o se imponga la sharía.

Como se ha encargado de recordar Amnistía Internacional en sus informes anuales, todavía queda mucho camino por recorrer. Esta organización denuncia que la situación de los derechos humanos no ha mejorado de manera sustancial en el mundo árabe en los últimos años y, a la vez, señala las tareas todavía pendientes.

Además de la aplastante victoria islamista, merece la pena destacarse la atomización política de los Parlamentos, que obliga al establecimiento de gobiernos de coalición entre las fuerzas islamistas y liberales; así como la ilegalización de los partidos oficialistas que habían disfrutado del monopolio político en Túnez y Egipto.

También hay que tener en cuenta el papel del ejército, que ya fue decisivo en el triunfo de las revueltas y que puede decidir tener un mayor protagonismo en el proceso político desarrollado tras la "Primavera árabe". De hecho, después de un periodo de tensas relaciones ${ }^{16}$ con los Hermanos Musulmanes, ganadores de las elecciones en Egipto, el 3 de julio de 2013, la Fuerzas Armadas derrocaron al presidente Mohamed Morsi, primer Jefe de Estado egipcio elegido en elecciones tras la caída del régimen dirigido por Hosni Mubarak.

Es difícil predecir la evolución de los acontecimientos en Egipto, donde la división de la sociedad en dos mitades es claramente patente, pero lo que la población necesita es una mejora de la situación económica, la implantación de un gobierno más transparente, que combata la corrupción, que garantice la estabilidad y, sobre todo, que normalice la situación.

16 ALGORA, María Dolores, "Los hermanos musulmanes después de la "Revolución del 25 de enero" : de los ideales del pasado a los desafíos políticos del presente", en Revista del Instituto Español de Estudios Estratégicos, n. ${ }^{\circ}$ 0, pp. 189-222, 2012 


\section{Conclusiones}

La "Primavera árabe" es un fenómeno poliédrico muy difícil de interpretar en toda su dimensión y complejidad. Hay diversos escenarios políticos, desde los países que comenzaron la marcha hacia la democracia hasta los que persisten en el autoritarismo. Estamos ante un proceso inconcluso, un camino emprendido pero repleto de incógnitas. Ahora bien, la transformación iniciada parece no tener vuelta atrás. Aunque por el momento haya afectado a tan sólo un puñado de países, la democratización progresiva del mundo árabe puede llegar a ser un proceso irreversible que acabe afectando, en mayor o menor medida, a todos los estados del área.

La población árabe perdió el miedo a sus gobernantes y a sus aparatos represivos y tomó las calles demandando mayores libertades y el fin de las autocracias. Las manifestaciones y las protestas fueron, ante todo, la expresión de un gran descontento hacia unos gobernantes que se perpetuaron en el tiempo y gestionaron los recursos estatales como si fueran de su propiedad. La sociedad logró superar el miedo y transformar la ira en acción.

Las rede sociales demostraron que, utilizadas como altavoces del disgusto de la población civil, son difíciles de silenciar y fueron determinantes en unos movimientos políticos sin líderes ni estructura aparentes. Los gobiernos intentaron diversas estrategias para evitar su difusión, desde la "desconexión" de Internet, el envío masivo de falsos sms o la usurpación de identidades en facebook, conscientes de la importancia del papel que estaban a jugar los nuevos medios; pero sus medidas no lograron ni ocultar lo que estaba sucediendo ni neutralizar los efectos de la insurrección.

Pese a estos logros, no debemos exagerar el protagonismo de las redes sociales, que sirven para movilizar y difundir pero no para hacer - o en todo caso, no solas - las revoluciones. No hay que sobrevalorar su papel, pues parece que las nuevas tecnologías suelen 
activar a los que ya eran activos o estaban sensibilizados en términos políticos o de participación. Tampoco puede hablarse de autonomía de las redes sociales con respecto a los medios tradicionales, ya que la cadena de televisión Al Jazeera fue un elemento decisivo en el éxito de las movilizaciones.

Las revueltas probaron que es preciso combinar las actuaciones en el espacio virtual con las protestas en el espacio físico, dado que es difícil mantener el entusiasmo de la agitación inicial originada desde el ciberactivismo. Por ello, es básico lograr la toma del espacio público, tal y como quedo de las manifestaciones masivas en las plazas. La suma del brazo virtual y físico de los movimientos sociales es lo que logra romper con el monopolio propagandístico emanado del poder. Se puede concluir que existe un nuevo ecosistema informativo, más abierto a la opinión de los ciudadanos y esto trae consigo importantes transformaciones en la comunicación política, tanto de los regímenes totalitarios como en los democráticos.

Otro elementos esencial para el éxito de las revoluciones populares es si se produce o no una fractura entre las élites dirigentes y las élites sustentadoras del régimen, lo que permite la caída de los dirigentes autoritarios. En especial, el papel del ejército es clave en el futuro de los países árabes.

La amplia movilización de la calle árabe en demanda de dignidad y libertades cuestiona la existencia de una "excepción islámica" según la cual los árabes serían refractarios a la democracia y proclives al despotismo. Las revueltas, que fueron esencialmente movimientos no violentos, expresaron a las claras que los pueblos árabes no son sujetos pasivos ni tampoco están contentos de vivir bajo el autoritarismo, lanzando el mensaje de que los obstáculos para la democratización no son ni permanentes ni insalvables.

Junto a una mejora de la situación económica, lo que demanda la población es el establecimiento de un nuevo contrato social basado 
en el respeto de las libertades y la consolidación de la democracia, pero también en la justicia social.

Una vez más ha quedado demostrado que la comunicación es el espacio en el que se construyen las relaciones de poder. Cualquier tipo de poder tiene que pasar por el espacio de la comunicación para llegar a las mentes de las personas, donde se desarrolla la batalla decisiva. Las redes sociales, como nuevos medios de relación, son también nuevos espacios de comunicación política, de propaganda y, en definitiva, frentes de la lucha por el poder. 